molhada" (que é outro motivo condutor de "Jardins de Cristais”). À frente de um bom livro está sempre um grande prefácio. Rodrigues teve a sorte de contar com a clarividência elegante da escrita do Professor João Lobo Antunes. Inevitavelmente retoma-se aqui a discussão das Duas Culturas, iniciada no século XIX por Matthew Arnold em "Literature and Science” (Rede Lecture de 1882) e retomada por C. P. Snow em 1959, noutra Rede Lecture. Arnold teve como opositor T. H. Huxley, o ‘bulldog de Darwin'; Snow contou com a oposição feroz do literato F. R. Leavis. Com uma diferença crucial: Arnold e Huxley eram amigos; Snow e Leavis detestavam-se. (Aliás, seria sempre difícil gostar de Leavis.) O próprio Snow tentou deitar água na fervura invocando uma terceira cultura - a das ciências sociais - que colmataria a brecha entre as culturas científica e humanista. A verdade é que a cultura é só uma, e abarca a química, a literatura, as outras ciências, as artes, a filosofia, a vida."Jardins de Cristais” é um belo exemplo desta cultura.

\title{
Mestre Carbono, O Cientista
}

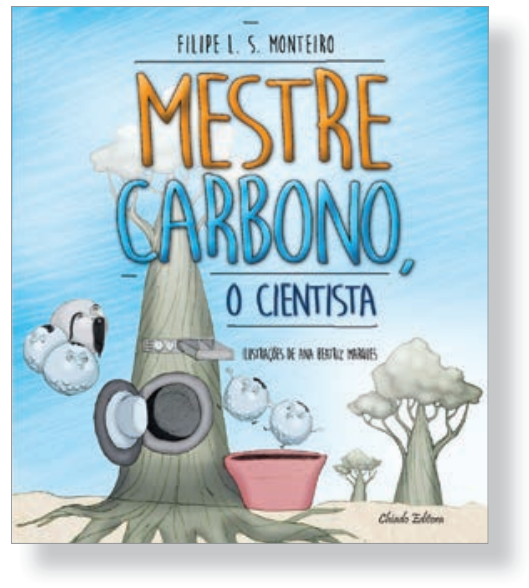

Muito mais do que o homem, interessa a Humanidade. A ela se dirige "Mestre Carbono, o Cientista", o drama das alterações climáticas, o aquecimento global, a salvação da Terra. Para isso trabalha Filipe Monteiro, o químico escritor licenciado em Química Analítica pela Universidade de Aveiro, vinte anos de trabalho na indústria química, como director de produção, director de qualidade e no desenvolvimento de novos produtos.

Afinal, o objectivo da Grande Obra alquímica é a aquisição da Pedra Filosofal ou do Elixir da Longa Vida; e, por muito que a alma de cientista de Filipe Monteiro afirme que não é alquimista, eu afirmo que ela é.

Conto de fadas para crianças? Ou uma escrita para adultos, num plano elevado, onde se realça e "manipula”, uma decifração oculta da Natureza? Saberemos nós quem de nós se serve como fonte de energia? E o que fazer quando percebemos a verdade?

“Mestre Carbono, o Cientista” é muito mais do que um texto bem delineado, bem escrito. Filipe Monteiro expressa claramente os seus objectivos: uma homenagem aos homens e mulheres que dedicam a sua vida a "fazer ciência” na busca de um mundo melhor; o alcance dramático das mudanças climáticas à escala global e a premência da salvação do mundo; a descoberta do composto químico salvador; ser cientista.

Todavia, o autor soube bem quanto o seu livro saiu valorizado pela ilustração, a todos os títulos brilhante, de Ana

\footnotetext{
*rmcgonc@gmail.com
}

\section{Raquel Gonçalves-Maia*}

Beatriz Marques. Como seria possível fazer passar as suas mensagens aos jovens e muito jovens se não existisse um poderoso Mestre Carbono, átomo redondo que nem lua cheia, "elemento robusto", de olhar sereno e confiante e farto bigode, de grafite feito, a inspirar chefia? E Hidrogénios de mão dada, Oxigénios sonolentos, enxames a compor moléculas, Glicose, Coenzima-A, Clorofila... Microscópios desenhados a preceito, balões, provetas e erlenmeyers estilizados e convidativos, três cientistas, uma equipa: Karen, Helena e Roberto. É o desenho de Ana Beatriz Marques que anima "Mestre Carbono, o Cientista", e permite a tão desejável interligação entre a Ciência e a Arte. Ah, a cultura... Excelente a qualidade!

“Ainda não foi desta”, diz Karen; diz Karen, e diz o átomo de Oxigénio. É uma mensagem de esperança: "Mas havemos de lá chegar”, retorque o Nitrogénio. “Não tenho dúvidas que o iremos alcançar”, diz Roberto. E com o erro se aprende e com muito suor se constrói. "Não repetiremos as ligações erradas”, diz Mestre Carbono.

Como se depreende, para além dos objectivos atrás citados, muitas são as mensagens - algumas muito simples, mas tão fundamentais! - que Filipe Monteiro nos transmite. Lava-se, arruma-se, mantém-se o laboratório operacional. Anota-se, analisa-se, reflecte-se, trabalha-se em grupo. $\mathrm{O}$ sono pode ser agitado, mas as motivações são sorridentes.

Retornando ao problema crucial - o apocalipse previsível da extinção da raça humana, se não de todas as raças, se 
mais clorofila não existir para de dióxido de carbono fazer oxigénio - podemos respirar de alívio, ou não?

O problema é tratado em dois níveis paralelos: o macro, a nível humano, e o micro, a nível dos átomos que se comportam como humanos - apenas um pouco mais inteligentes... A metáfora é bem conseguida.

E a originalidade surge, não tanto na temática que já é bem conhecida de todos nós, mas na forma escolhida pelo autor para que ela tenha impacte sobre todos nós: são os "pequeninos" que ensinam os "grandes”; são os átomos que conduzem as investigações da equipa, são os filhos que vão ensinar os pais...

O autor tem plena consciência da dificuldade da tradução escrita desta inversão de poderes. E mais sabe - que nem sempre conseguiu a interpretação perfeita, porque ela simplesmente não existe...

Mas os jovens aprendem, estão cá para isso... E, se não se sentirem familiarizados com certos termos, mais científicos ou mais técnicos, podem sempre recorrer ao glossário que o autor, inspirado, introduziu no livro. E se, mesmo assim, ainda considerarem as explicações insuficientes recorram aos pais, aos professores, aos amigos - ao Filipe! - que todos nós temos o dever de os elucidar, ao mesmo tempo que - quem diria! mais sensibilizados ficaremos para o problema do "efeito de estufa” e suas maléficas consequências.

É muito escasso o trabalho de divulgação científica em Portugal, para mais a nível infanto-juvenil. Aplaudir a ousadia de Filipe Monteiro que, por artes mágicas, nos devolveu o “ar puro” na Terra, é um saudável imperativo.

\section{Actualidades Científicas}

\section{CÁlCULOS PREVÊEM GRAFENo PENTAGonaL}

Investigadores chineses propuseram a existência de um novo alótropo 2D de carbono, constituído por pentágonos, o qual designaram por “penta-grafeno”. Tal como o grafeno, o penta-grafeno consiste numa folha plana de átomos de carbono em que estes se encontram dispostos segundo um padrão pentagonal, originando algumas propriedades físicas interessantes.
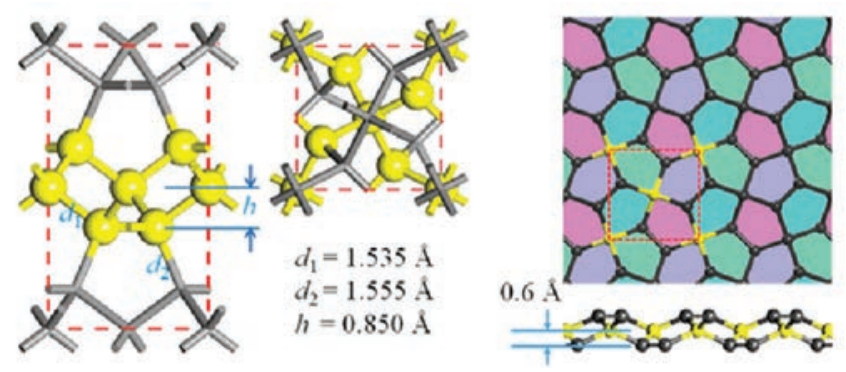

Estudos teóricos realizados pela equipa de investigação mostraram que a versão pentagonal do grafeno será razoavelmente estável e também mais forte e capaz de resistir a temperaturas mais elevadas, até $730^{\circ} \mathrm{C}$, do que o grafeno convencional. Além disso, terá propriedades semicondutoras, ao contrário do grafeno convencional que é um condutor altamente eficiente que tem de ser quimicamente modificado para ser transformado em semicondutor. Com esta descoberta, poder-se-á abrir uma porta na produção selectiva de nanotubos de carbono (CNTs) semicondutores uma vez que os métodos actuais de síntese de CNTs a partir do grafeno convencional produzem geralmente uma mistura de CNTs condutores e semicondutores, dependendo da orientação dos hexágonos quando uma folha de grafeno é enrolada. Curiosamente, o penta-grafeno também parece ter propriedades auxéticas, ou seja, ao ser esticado numa determinada direcção, expande quer nessa direcção quer na sua perpendicular, ao contrário do que se observa na grande maioria dos materiais, grafeno convencional incluído, em que se observa uma contracção na direcção perpendicular àquela em que são esticados.

O conjunto destas propriedades sugere uma série de potenciais aplicações para o penta-grafeno, nomeadamente na área da nano-electrónica, biomateriais e em tecnologias espaciais, tal como sugerido por Qian Wang, líder da equipa de investigação. Philip Feng da Universidade Case Western Reserve, em Cleveland, Estados Unidos, que trabalha com muitos nanomateriais 2D, espera que o penta-grafeno possa ser sintetizado. "A estrutura é muito intrigante e fascinante”, referiu, acrescentando que "se este penta-grafeno puder ser isolado ou sintetizado, poderá ser outra grande contribuição para a família de estruturas 2D”.

(adaptado de “Calculations predict pentagonal graphene”, http://www.rsc.org/chemistryworld/2015/02/calculations-predict-pentagonal-graphene e de Shunhong Zhanga, Jian Zhouc, Qian Wanga, Xiaoshuang Chend, Yoshiyuki Kawazoef, Puru Jenac. Proc. Natl. Acad. Sci. USA 112 (2015) 2372-2377)

Paulo Mendes (pjgm@uevora.pt) 